\title{
EFFECT OF DIFFERENT REPAIR PROTOCOLS ON BOND STRENGTH TO DIRECT AND INDIRECT RESIN COMPOSITE
}

\author{
Shereen Assem El-Sherif*, Mohamed Riad Farid** and Mohamed Fouad Haridy ${ }^{* * *}$
}

\begin{abstract}
Objective: This study was carried out to investigate the effect of different surface treatment protocols on bond strength of nano-composite as a repair material to two types of resin composite either direct composite or indirect resin composite blocks for CEREC system.

Materials and methods: Total of 80 composite discs were prepared and were divided into two main groups (40 each) according to the type of composite used $(C)$, nano-filled composite $\left(\mathrm{C}_{1}\right)$ and composite blocks for CEREC system $\left(\mathrm{C}_{2}\right)$. All specimens were aged for one month in a distilled water solution at $37^{\circ} \mathrm{C}$. Each group was sub-divided into four subgroups (10 each) according to the surface treatment protocol $(\mathrm{T})$ that was done on the discs, either no treatment $\left(\mathrm{T}_{0}\right)$ (control), application of Ortho phosphoric acid $\left(\mathrm{T}_{1}\right)$, Hydrofluoric acid $\left(\mathrm{T}_{2}\right)$ and Sandblasting $\left(\mathrm{T}_{3}\right)$. Each sub group was subdivided into two classes (5 each) according to silane application $\left(\mathrm{S}_{1}\right)$ or without $\left(\mathrm{S}_{0}\right)$. Nanofilled resin composite (Filtek Z350 XT, 3M ESPE) was used as a repair material. Microshear bond strength testing ( $\mu$-SBS) was done using Universal testing machine. Failure modes of the fractured specimens were analyzed using scanning electron microscope (SEM). $\mu$-SBS results were analyzed using ANOVA, Tukey's post-hoc and Student t-tests.
\end{abstract}

Results: The indirect resin composite of the hydrofluoric acid group with silane showed the highest $\mu$-Shear bond strength mean value $(31.35 \pm 5.1)$ while the direct composite of the etchant group with no silane showed the lowest $\mu$-Shear bond strength mean value (20.8 \pm 4.5$)$. Regarding the composite type, $\boldsymbol{C}_{2}$ recorded statistically significant $(\mathrm{P}<0.05)$ higher $\mu$-shear bond strength mean value $(27.05 \pm 6.1 \mathrm{MPa})$ than $\boldsymbol{C}_{\boldsymbol{1}}(23.82 \pm 6.2 \mathrm{MPa})$. Regarding the surface treatment, $\boldsymbol{T}_{3}$ recorded statistically non-significant $(\mathrm{P}>0.05)$ highest $\mu$-shear bond strength mean value $(26.72 \pm 0.78 \mathrm{MPa})$ followed by $\boldsymbol{T}_{1}(25.77 \pm 2.55 \mathrm{MPa})$ then $\boldsymbol{T}_{2}(24.71 \pm 1.44 \mathrm{MPa})$ while $\boldsymbol{T}_{0}$ recorded statistically nonsignificant $(\mathrm{P}>0.05)$ lowest $\mu$-shear bond strength mean value $(24.54 \pm 1.7 \mathrm{MPa})$. Regarding the silane application, $S_{1}$ recorded statistically non-significant $(\mathrm{P}>0.05)$ higher $\mu$-shear bond strength mean value $(26.28 \pm 1.57 \mathrm{MPa})$ than $S_{0}(24.59 \pm 1.66 \mathrm{MPa})$.

Conclusions: The Cojet treatment of the resin composite improved the bond strength of different types of resin composite. The type of resin composite used for repair influences the bond strength to the repaired resin composite. Silane application to repaired resin composite affects the bond strength to it with different treatment protocols.

KEY WORDS: Computer-aided design/computer-aided manufacturing esthetic blocks, nanofilled resin composite, microshear bond strength, repair, scanning electron microscopy, silane.

\footnotetext{
* Department of Operative Dentistry, Cairo University, Cairo, Egypt
} 


\section{INTRODUCTION}

Composites are presently the most popular tooth colored materials, which are used in almost all types and sizes of restorations. Such restorations are accomplished with minimal loss of tooth structure, little or no discomfort, relatively short operating time, and modest expense to the patient. Composites and the acid-etch technique represent two major advances. Adhesive materials that allow bonding to enamel and dentin further simplify restorative techniques. (Roberson et al; 2006).

The introduction of indirect laboratory composite has been a great development in dentistry. These materials have been promoted as a hybridization of composite and ceramic technologies, although they are essentially still a composite resin matrix with differing filler components. Strong claims have been presented by some manufacturers regarding refinements in esthetics and improvements in physical properties, including wear resistance. The type of matrix and the degree to which conversion occurs during polymerization also influence the properties, especially when aging occurs in the oral environment. The presence of filler particles increases the compressive strength and hardness of the polymer matrix. (Mandikos et al 2001).

Recently there has been a shift towards maintenance and repair rather than the replacement of the deteriorating yet serviceable restorations in patients who should receive minimum intervention. Composite restoration repairs may be considered the treatment of choice for surface discoloration of existing restorations, small areas of recurrent caries along the margin of sound composite restoration, or when complete removal of a very large composite restoration would unnecessarily jeopardize the health of a toot.( Qualtrough et al ;2005)

However some other factors like clinical situations, cost, esthetic, extent and mode offailure, failure site, quality of existing restoration, cause of failure and expected age of the existing restoration affect the treatment plan. Bond strength of incrementally built upcomposite on fresh, uncontaminated or unprepared resin composite is similar to cohesive strength of the material. However, there is the possibility that repair may lead to a weak restoration. It seems because of lack of air-inhibited layer on surface, the degree of unreacted carbon double bond is lower and chemical bonding between fresh and aged composite is not a reliable bond. (Tabatabaei et al; 2004)

Different protocols of repair with various surface conditioning methods have been developed to improve the adhesion of aged and repaired composite resins. Surface treatment protocols include acid etching with hydrofluoric or phosphoric acid, The use of coarse burs, silicon paper, green carburandum stone and sandblasting with different types and sizes of particles are quite effective in roughening the aged composite surface prior to bonding using different types of adhesive resins.(Eren et al ;2013)

Therefore it was felt that a study aiming to investigate the effect of different repair protocols on bond strength to direct and indirect resin composite might be of value.

\section{MATERIALS AND METHODS}

\section{Specimen preparation}

Eighty discs were constructed from direct composite resin and indirect esthetic restorative blocks. Forty discs were constructed from Nanofilled resin composite, shade A2 (Filtek Z350XT; 3M ESPE), and the remaining discs were constructed from Nanohybrid resin composite blocks, shade A2, size 14 (Paradigm $^{\mathrm{TM}}$ MZ100; 3M ESPE), which are designed for Cerec CAD/CAM system. Materials composition, manufacturer, and lot number are presented in Table 1.

Discs of the direct composite (Filtek Z350XT, $3 \mathrm{M}$ ESPE) of $1 \mathrm{~cm}$ diameter and $2 \mathrm{~mm}$ thickness were prepared using Teflon mold of the same dimensions. The resin composite was packed into the mold using gold plated composite applicator(Thomson. 
TABLE (1) Materials, composition, manufacturer, and lot number

\begin{tabular}{|c|c|c|c|}
\hline Material & Composition & Manufacturer & Lot number \\
\hline $\begin{array}{l}\text { CAD/CAM composite } \\
\text { blocks Paradigm } \\
\text { MZ100 }\end{array}$ & $\begin{array}{l}\text { Polymermatrixconsists of bisGMA(Bisphenol } \\
\text { A diglycidyl ether } \\
\text { dimethacrylate) and TEGDMA (tri } \\
\text { (ethyleneglycol) dimethacrylate), } \\
\text { ternary initiator system and } 85 \mathrm{wt} \% \text { ultrafine } \\
\text { zirconiasilica ceramic } \\
\text { particles that reinforce the highly crosslinked } \\
\text { polymeric matrix }\end{array}$ & $\begin{array}{c}\text { 3MESPE, St. Paul, } \\
\text { MN, USA }\end{array}$ & 20090112 \\
\hline $\begin{array}{c}\text { Filtek }^{\mathrm{TM}} \mathrm{Z} 350 \\
\text { XT universal } \\
\text { restorative } \\
\text { material }\end{array}$ & $\begin{array}{l}\text { Organic part: } \\
\text { BisGMA, UDMA, TEGDMA, PEGDMA } \\
\text { and BisEMA resins } \\
\text { Inorganic part: } \\
72.5 \% \text { by wt ( } 55.6 \% \text { by volume) The fillers } \\
\text { are a combination of a nonagglomerated/ } \\
\text { nonaggregated } 20 \mathrm{~nm} \text { silica filler, a } \\
\text { nonagglomerated/nonaggregated } 4 \text { to } 11 \mathrm{~nm} \\
\text { zirconia filler and an aggregated zirconia/ } \\
\text { silica cluster filler (comprised of } 20 \mathrm{~nm} \text { silica } \\
\text { and } 411 \mathrm{~nm} \text { zirconia particles). }\end{array}$ & $\begin{array}{c}\text { 3MESPE, St. Paul, } \\
\text { MN, USA }\end{array}$ & N313041 \\
\hline $\begin{array}{l}\text { Single bond } \\
\text { universal } \\
\text { adhesive }\end{array}$ & $\begin{array}{l}\text { MDP Phosphate Monomer, Dimethacrylate } \\
\text { resins, HEMA, Vitrebond }{ }^{\mathrm{TM}} \text { Copolymer, } \\
\text { filler, Ethanol, water, initiators and silane }\end{array}$ & $\begin{array}{c}\text { 3MESPE, St. Paul, } \\
\text { MN, USA }\end{array}$ & 494759 \\
\hline $\begin{array}{c}\text { Scotchbond, universal } \\
\text { etchant }\end{array}$ & $32 \%$ Orthophosphoric acid & $\begin{array}{c}\text { 3MESPE, St. Paul, } \\
\text { MN, USA }\end{array}$ & 525534 \\
\hline $\begin{array}{c}\text { Ultradent porcelain } \\
\text { etch }\end{array}$ & 9\% Hydrofluoric acid & $\begin{array}{l}\text { Ultradent Products } \\
\text { Inc. USA }\end{array}$ & B9MV6 \\
\hline Ultradent silane & Silane coupling agent & $\begin{array}{l}\text { Ultradent Products } \\
\text { Inc. USA }\end{array}$ & B9MV6 \\
\hline
\end{tabular}

Bis-GMA: Bisphenyl glycidyl methacrylate,UDMA: Urethane dimethacrylate, TEGDMA: Triethylene glycol dimethacrylate, PEGDMA: Polyethylene glycol dimethacrylate, HEMA: 2 hydroxyethyl methacrylate

USA) and light cured for 20 seconds from each side using Bluephase lightemitting diode curing unit C5 (IvoclarVivadent AG,Schaan, Liechtenstein) at a light intensity of $500 \mathrm{~mW} / \mathrm{cm}^{2}$. Discs of the indirect composite (Paradigm ${ }^{\mathrm{TM}}$ MZ100; 3MESPE) of $2 \mathrm{~mm}$ thickness were obtained by sectioning the blocks using a low speed isomet saw (Isomet 1000, Buehler Ltd., Lake Bluff, IL, USA). The discs were embedded in acrylic resin blocks using plastic molds with the surfaces to be repaired facing upwards.

\section{Aging of the specimens}

The discs were artificially aged by storing them in distilled water for one month at $37^{\circ} \mathrm{C}$. The water was changed every 3 days to prevent bacterial growth.

\section{Specimen grouping}

The eighty standardized discs were divided into two main groups (40 each) according to type of the material either direct resin composite or indirect resin composite blocks for CEREC system. 
Each group was divided into four subgroups (10 each) according to the surface treatment of the prepared discs either no surface treatment, etching using orthophosphoric acid, etching using hydrofluoric acid and sandblasting . Each subgroup was divided into two classes (5 each) according to application of silane coupling agent before the adhesive or not.

\section{The surface treatment of the discs}

- Group I (C): no surface treatment was done.

- GroupII (OF): 32\% orthophosphoric acid etching for 15 seconds (Scotchbond, universal etchant, 3M ESPE) rinsed for $15 \mathrm{~s}$ and airdried for $5 \mathrm{~s}$

- GroupIII (HF): 9\% hydrofluoric acid etching for 90 seconds (Ultradent porcelain etch; Ultradent, USA), rinsed for $15 \mathrm{~s}$ and air-dried for $5 \mathrm{~s}$.

- Group IV (SC): Silica coating was done using an intraoral air-abrasion device (CoJet; 3M ESPE, Seefeld, Germany) filled with $30 \mu \mathrm{m}$ alumina particles coated with silica (CoJetSand, 3M ESPE AG, Seefeld, Germany) from a distance of approximately $10 \mathrm{~mm}$ at a pressure of 2.5 bars for $10 \mathrm{~s}$. Following surface conditioning, loose particles were gently airblown.

\section{Silane application}

In the sub-groups in which the silane coupling agent (Ultradent silane, USA) was applied with a brush, left undisturbed for $1 \mathrm{~min}$, and then airdried.

\section{Application of the adhesive system}

Following the four different surface treatments, all groups received one coat of a silane containing bonding agent (Single Bond Universal adhesive, 3M ESPE), which was applied for 15 seconds with gentle agitation using a fully saturated applicator sponge and gently air thinned for 5 seconds to evaporate the solvent.

\section{Preparation for the micro shear bond testing}

For microshear bond strength testing; at first the adhesive will be applied to the resin composite discs and prior to light curing of the bonding agent. Micro-cylinders that were cut from tygon tubes (Norton Performance Plastic Co. Cleveland of USA) with an internal diameter of $0.8 \mathrm{~mm}$ and a height of $1 \mathrm{~mm}$ were mounted on the treated surfaces to restrict the bonding area. Six micro-cylinders were mounted on each disc. Light curing of the bonding resin was attempted for 10 seconds using Bluephase C5 (IvoclarVivadent AG,Schaan, Liechtenstein) lightemitting diode curing unit for 10 seconds at a light intensity of $500 \mathrm{~mW} / \mathrm{cm} 2$. Nanofilled resin composite (Filtek Z350XT, 3M ESPE), shade A2, was packed into the cylinder Lumen using thin endodontic plugger, and a plastic matrix strip was placed over the resin composite and gently pressed flat and lightcured for 20 seconds using the same light curing unit according to manufacturer instructions.

The specimens were stored at room temperature for one hour prior to removing the tygon tubes using a blade. In this manner, very small cylinders of resin, approximately $0.8 \mathrm{~mm}$ in diameter and 1 $\mathrm{mm}$ in height, were bonded to the treated surfaces.

\section{Micro-shear bond strength testing}

Each acrylic block containing the embedded composite disc with its own bonded composite micro-cylinders was secured with tightening screws to the lower fixed compartment of a materials testing machine (Model LRX-plus; Lloyd Instruments Ltd., Fareham, UK) with a loadcell of $5 \mathrm{kN}$ and data were recorded using computer software (NexygenMT Lloyd Instruments). A loop prepared from an orthodontic wire (0.014" in diameter) was wrapped around the bonded micro-cylinder assembly as close as possible to the base of the microcylinder and aligned with the loading axis of the upper movable compartment of the testing machine. 
A shearing load with tensile mode of force was applied via materials testing machine at a crosshead speed of $0.5 \mathrm{~mm} / \mathrm{min}$. The relatively slow crosshead speed was selected in order to produce a shearing force that resulted in debonding of the microcylinder along the substrate-adhesive interface. The load required to debonding was recorded in Newton.

\section{Micro-Shear bond strength calculation}

The load at failure was divided by bonding area to express the bond strength in MPa:

$$
\boldsymbol{\tau}=\mathbf{P} / \pi \mathbf{r}^{2}
$$

Where; $\boldsymbol{\tau}=$ bond strength (in $\mathrm{MPa}$ )

$$
\begin{aligned}
& \mathbf{P}=\text { load at failure (in } \mathrm{N} \text { ) } \\
& \boldsymbol{\pi}=3.14 \\
& \mathbf{r}=\text { radius of micro-cylinder (in } \mathrm{mm} \text { ) }
\end{aligned}
$$

\section{Scanning electron microscope analysis (SEM)}

The topography of all substrates was analyzed using scanning electron microsopy SEM.

\section{Statistical analysis}

Data analysis was performed in several steps. Initially, descriptive statistics for each group results.

Three-factor analysis of variance ANOVA test of significance for comparing variables affecting mean values (construction method, surface treatment and silanization).

One way ANOVA followed by pair-wise Tukey's post-hoc tests were performed to detect significance between surface treatment subgroups. Student t-test was used to detect significance between construction groups and silane subgroups.

Statistical analysis was performed using Aasistat 7.6 statistics software for Windows (Campina Grande, Paraiba state, Brazil). P values $\leq 0.05$ are considered to be statistically significant in all tests.

\section{RESULTS}

Regardless to surface treatment or silanization, totally it was found that In-direct group recorded statistically significant $(\mathrm{P}<0.05)$ higher $\mu$-shear bond strength mean value $(27.05 \pm 6.1 \mathrm{MPa})$ than Direct group (23.82 $\pm 6.2 \mathrm{MPa})$. Figure(1)

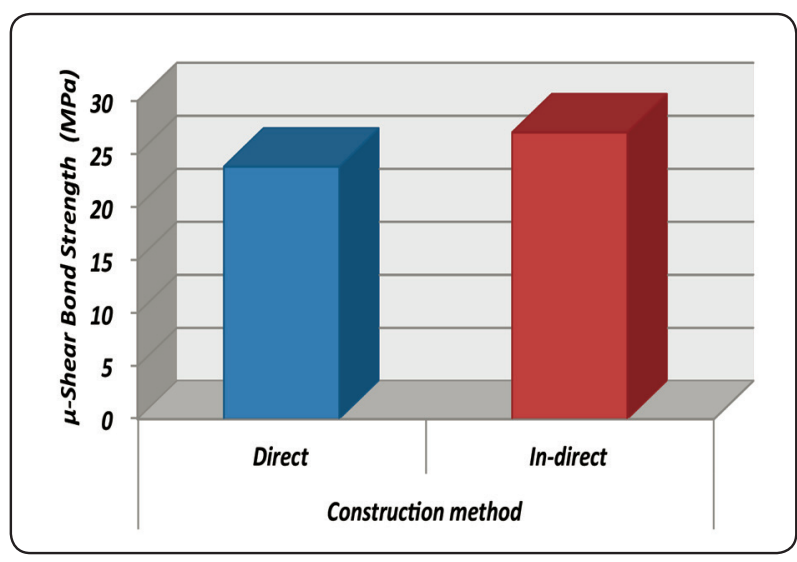

Fig. (1) A column chart of total $\mu$-shear bond strength mean values as function of restoration type

Regardless to restoration type or surface treatment, totally it was found that silanized group recorded statistically non-significant $(\mathrm{P}>0.05)$ higher $\mu$-shear bond strength mean value $(26.28 \pm 1.57 \mathrm{MPa})$ than non-silanized group $(24.59 \pm 1.66 \mathrm{MPa})$. Figure (2)

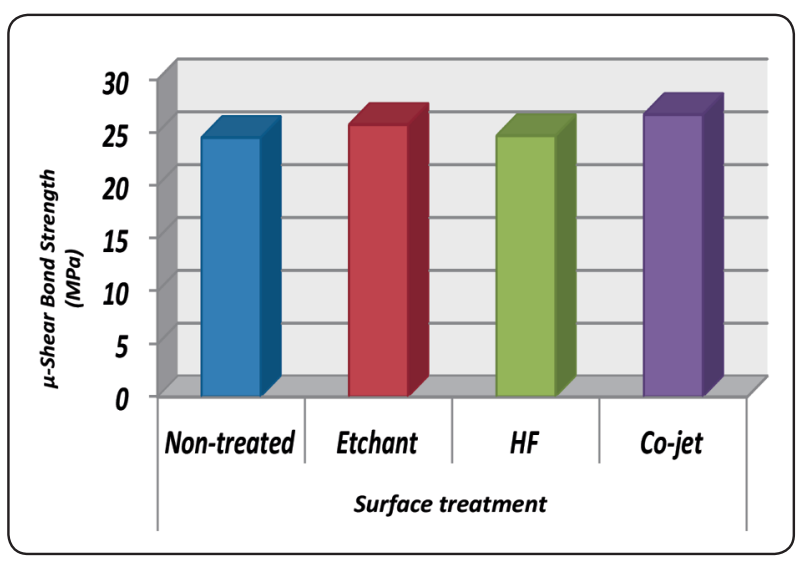

Fig. (2) A column chart of total $\mu$-shear bond strength mean values as function of surface treatment 
Irrespective of restoration type or silanization, totally it was found that Co-jet treated group recorded statistically non-significant $(\mathrm{P}>0.05)$ highest $\mu$-shear bond strength mean value $(26.72 \pm 0.78 \mathrm{MPa})$ followed by Etchant treated group $(25.77 \pm 2.55 \mathrm{MPa})$ then $\mathrm{HF}$ treated group $(24.71 \pm 1.44$ $\mathrm{MPa}$ ) while Non-treated group recorded statistically non-significant $(\mathrm{P}>0.05)$ lowest $\mu$-shear bond strength mean value $(24.54 \pm 1.7 \mathrm{MPa})$. Figure (3)

Descriptive statistics of $\mu$-shear bond strength (MPa) showing mean values and standard deviation for both direct and indirect restorations as function of surface treatment and silanization are summarized in table (2) and graphically drawn in figure (4).

Ultra-morphological characterization of the surface topography

Four representative discs were prepared from both direct and indirect composite discs. The first; left as control, the second; Etching with Orthophosphoric acid, the third; Etching with Hydrofluoric acid, and the forth; Co-jet. The parameters of the treatments applied were similar to that of bond strength testing. Fiures (5\&6)

TABLE (2) Descriptive statistics of $\mu$-shear bond strength results (Mean values \pm SDs) for both direct and indirect method as function of surface treatment and silanization

\begin{tabular}{|c|c|c|c|c|c|}
\hline \multicolumn{2}{|c|}{} & \multicolumn{2}{c|}{ No silane } & \multicolumn{2}{c|}{ Silane } \\
\cline { 2 - 6 } & Diriables & Direct & In-direct & Direct & In-direct \\
\hline \multirow{3}{*}{ Surface treatment } & Non-treated & $21.94 \pm 3.7$ & $25.55 \pm 4.9$ & $23.75 \pm 4.9$ & $26.93 \pm 3.9$ \\
\cline { 2 - 6 } & Etchant & $20.8 \pm 4.5$ & $29.48 \pm 3.5$ & $25.64 \pm 2.1$ & $27.15 \pm 3.4$ \\
\cline { 2 - 6 } & HF & $22.73 \pm 4.9$ & $21.31 \pm 2.6$ & $23.81 \pm 3.1$ & $31.35 \pm 5.1$ \\
\cline { 2 - 6 } & Co-jet & $26.24 \pm 5.1$ & $28.89 \pm 5.8$ & $25.65 \pm 3.9$ & $25.99 \pm 3.2$ \\
\hline
\end{tabular}

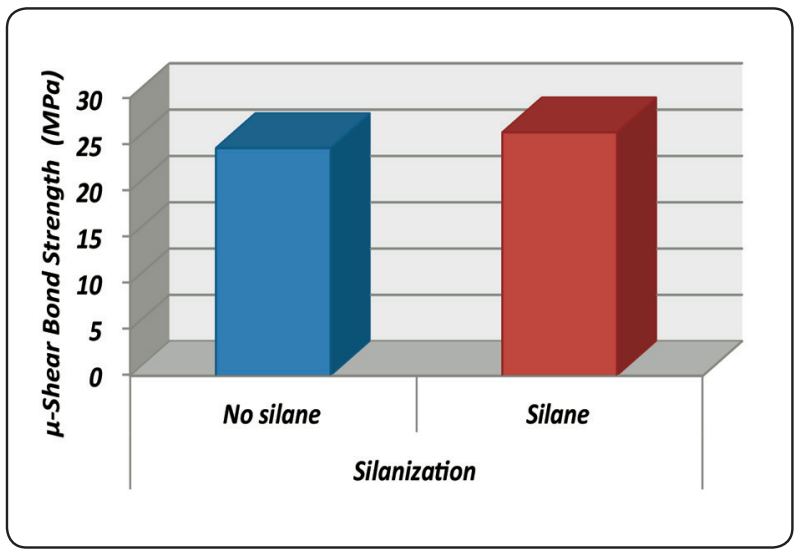

Fig. (3) A column chart of total $\mu$-shear bond strength mean values as function of Silanization

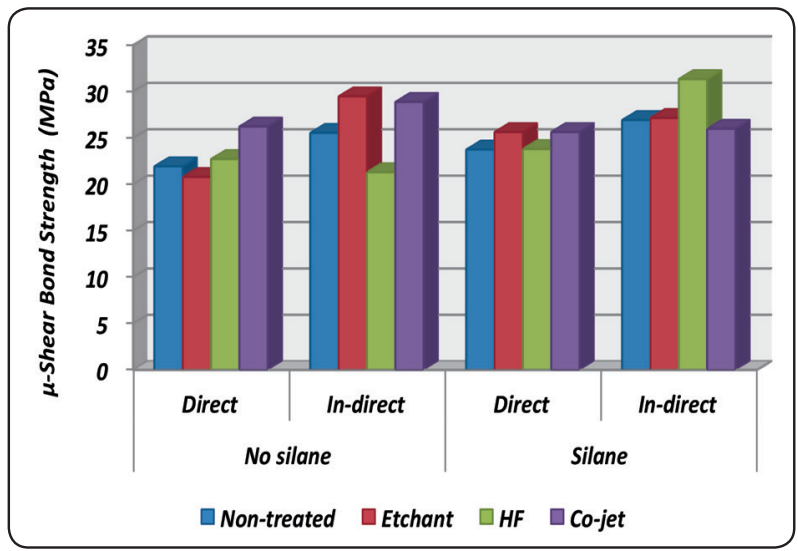

Fig. (4) Histogram of $\mu$-shear bond strength mean values for both direct and indirect method as function of surface treatment and silanization 


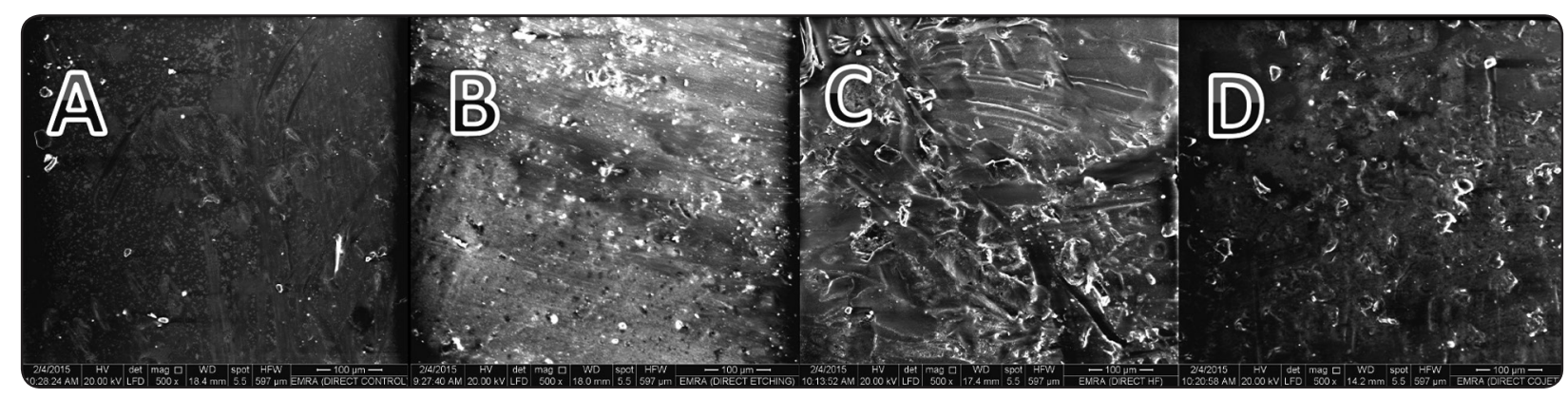

Fig. (5) SEM photos representing the surface topography of direct composite blocks. A: control; the untreated surface showed flat and relatively smooth surface with some shallow striations. B: etchant; the surface became very rough with multiple irregularities and shallow pores. C: hydrofluoric acid; many scars with very rough with multiple relatively deep irregularities and cracking. D: cojet; many grooves as well as smear layer and abrasion scars and silica deposits.

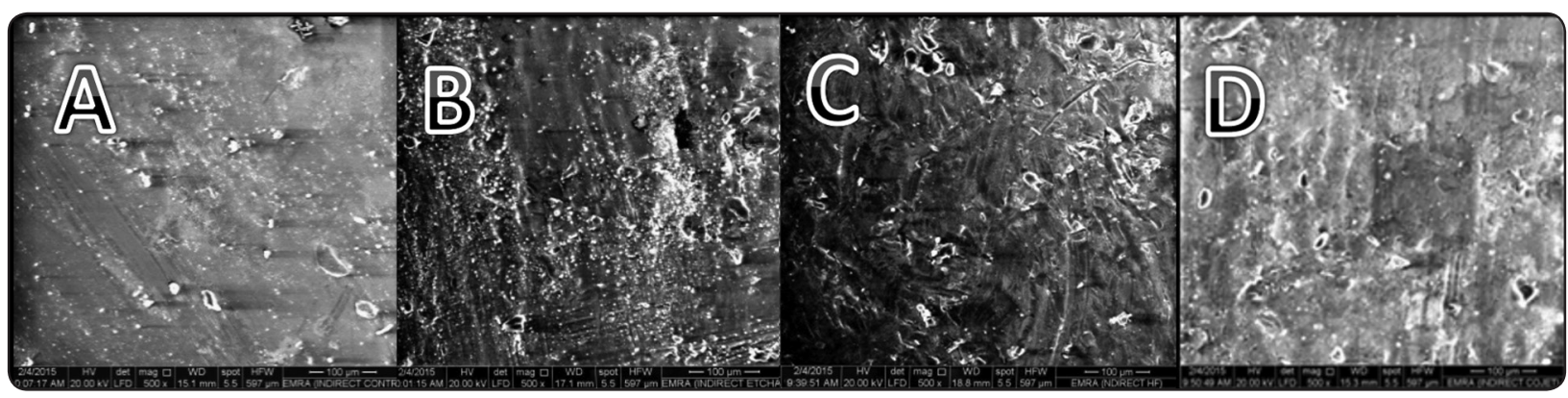

Fig. (6) SEM photos representing the surface topography of indirect composite blocks. A: control; the untreated surface showed flat and relatively smooth surface with some shallow grooves. B: etchant; the surface became very rough with multiple grooves and shallow pores. C: hydrofluoric acid; many cracks with very rough with multiple relatively deep scars and grooves. D: cojet; many vertical grooves as well as smear layer and many silica deposits.

\section{DISCUSSION}

Adhesive dentistry has brought into perspective the possibility of the repair of pre-existing restorations rather than their complete replacement. Repair of resin composite considered as a more conservative alternative treatment modality than replacement, due to several disadvantages of replacement as waste of time, money and effort, and unnecessary removal of sound tooth structure .The re-restoration cycle generally results in weakening of the tooth structure and subsequently in tooth loss (Gordan, 2001) Repair had significantly improved the longevity of the composite resin restorations.

In the present study, the repair potential of both conventional composite resin and the machinable $\mathrm{CAD} / \mathrm{CAM}$ esthetic blocks was assessed. Moreover, two clinical situations were simulated, one being the situation where the clinician repairs the substrate resin composite with that of the same material and the second where the nature of the substrate resin composite is not known and therefore a dissimilar material was selected.

Using nano technology is of great interest in resin composites research, due to enhancement of mechanical properties and the reduction of the polymerization shrinkage (Ikejima et al in 2003). Moreover, Advances in CAD/CAM technology offers the dentist the opportunity to prepare, design, and fabricate esthetic indirect restorations in a single appointment, without the need for making impressions, provisional restorations, or dental laboratory support. 
On the contrary to significant improvement in physical properties of these types of restorations, bond strength of these restorations with resins is still a problem (Nilsson et al 2000). The reasons for reduced bond strength could be increased degree of conversion and decreased unreacted methacrylate groups available for bond due to secondary polymerization methods like light, high temperature and pressure. (DeSchepper et al 1993)

Silanes are adhesion promoters that contain two different reactive functional groups that can react and couple with various inorganic and organic materials. They are used to increase the union of dissimilar materials. The hydrolysable functional groups react to the surface hydroxyl groups of inorganic substrates creating a siloxane bond (Si-O-Si). The organic non-hydrolysable functional group with a carbon-carbon double bond can polymerize with resin composite monomers containing double bonds. It could be assumed that there should be equilibrium between the amount of the hydroxyl groups of inorganic substrates exposed and the hydrolysable functional groups present in the silane. Thus, the quality of the siloxane bond formed is determined by the concentration of the silane solution and the surface pre-treatment protocol that determines the amount of hydroxyl groups exposed. (Lung \& Matinlinna 2012)

Clinically intraoral surface pretreatment of an aged resin composite has two purposes: to remove the superficial layer altered by the saliva exposing a clean, higher energy composite surface and to increase the surface area through creation of surface irregularities (Jounior et al, 2009). According to Brosh et al in 1997 the union between the old and the new composite in a repair situation may occur by three distinct mechanisms through a chemical bonding either with the organic matrix or with the exposed filler particles also it may be through micromechanical retention to the treated surface. Bonding to the resin matrix relies on the unconverted $\mathrm{C}=\mathrm{C}$ double bonds remaining in the surface of the aged composite. Three different surface treatment strategies besides a control group were employed in the current study.

The present study regarding the type of the repaired restoration, the indirect resin composite revealed higher bond strength to the repair material than the direct resin composite. This might be attributed to the effect of aging process on the direct resin composite starting the degradation process of the resin which resulted in polymer swelling, plasticizing and weakening of the polymer network affect the nature and the mechanical properties of the repaired substrate (Pashley et al 2004 and Pashely et al 1999). On the other hand, the effect of the storage on the indirect resin composite appeared to be less than that on the direct one that might be due to its compositional stability and the higher degree of conversion. These findings were in disagreement with Da fonte carreiro et al 2004.

Concerning the surface treatment protocols, the silica coating protocol (Cojet) showed the higher bond strength results. This might be attributed to the mechanics of action of this protocol. In this protocol the substrate was subjected to fast and compressed air blasts with silica coated alumina particles. The micro-irregularities cause by the impact of these particles as well as formation of fresh $\mathrm{SiO} 2$ layer on the substrate surface increase the reactivity of this surface and make it ideal for bonding especially when preceded with silane coating step (Zaghloul et al, 2014).

These findings were in agreement with (Passos et al 2007, Moezizadeh 2012, Haning 2006) and in disagreement with (Tabatabaei 2004, Boushlier 1999 ).

Regarding the silanization step, application of silane coupling agent before the bonding agent improved the bond strength of the repair material to the repaired substrate. Silanes are adhesion promoters that contain two different reactive functional groups that can react and couple with various inorganic and organic materials. They are 
used to increase the bonding of dissimilar materials. A siloxane bond ( $\mathrm{Si}-\mathrm{O}-\mathrm{Si})$ is created between the hydrolysable functional groups and the surface hydroxyl groups of inorganic substrates. The organic non-hydrolysable functional group with a carboncarbon double bond can polymerize with resin composite monomers containing double bonds. A balance between the amount of the hydroxyl groups of inorganic substrates exposed and the hydrolysable functional groups present in the silane-coupling agent must be considered. Therefore, the strength of the formed siloxane bond is determined by the concentration of the silane solution and the surface treatment protocol that determine the amount of hydroxyl groups exposed. (Matinlinna and Vallittu, 2007; Lung and Matinlinna; 2012).

Concerning the direct resin composite after aging for one month, the silica coating surface treatment protocol (Cojet) revealed the highest bond strength of the repair material both with and without a silanization step. With no silanization step, the formed micro irregularities on the surface due to silica particles collision and formation of the silica coated layer at the outermost surface as well as presence of the silane coupling agent in the universal adhesive promoted the adhesion to the repaired direct resin composite. These findings were in agreement with Haning et al 2006.

While for the silanized group, the bond strength to the substrate was high but insignificantly less than that of the non-silanized group. This could be explained by formation of covalent bond between the formed silica-coated layer and the resin composite used as repair material. The increased amount of silane coupling agent from the separate application step as well as that found in the universal adhesive might affect its adhesion promotion capacity. These findings were in agreement with Tabatabaei et al 2004 and in disagreement with Bonstein et al 2005.

Regarding the indirect resin composite, etching with phosphoric acid as well as silica coating protocols showed the highest bond strength of the repair material. The attribution might be due to the retentive surface texture obtained after these protocols generating micromechanical interlocking with the substrate. It could be assumed that the micro irregularities generated by phosphoric acid etching and silica coating were of depths that could be wetted and impregnated by the adhesive without separate silanization step. On the contrary, etching with hydrofluoric acid might generate deeper retentive pores that could not be wetted or infiltrated by the adhesive impairing the bond strength of the resin composite to the etched surface. This result was reversed after application of silane coupling agent separately before the adhesive. According to the previous assumption, the increase of depth of retentive micro irregularities after HF etching might not affected by the high concentration of silane coupling agent after its application separately and that found in the adhesive. Additionally, the silica coating (Cojet) showed the lowest bond strength with the substrate that might be explained by the negative effect of the additional silanization step that led to the existence of unreacted hydrolysable function groups due to low amount of hydroxyl groups exposed forming week siloxane bond. Moreover, the increased thickness of silane layer might have compromised the repaired bond strength. Similar findings were reported by Bonstein et al 2005 and Brosh et al 1997.

Under the conditions of this study, the following conclusions might be evident:

1. The type of substrate material affected the repair bond strength with different repair protocols.

2. The Cojet treatment of the resin composite improved the bond strength of different types of resin composite

3. Lack of surface treatment of the resin composite before repair affected the bond strength to the repaired resin composite.

4. Silane application to repaired resin composite affected the bond strength to it with different treatment protocols. 


\section{RECOMMENDATIONS}

1- Several studies are needed to test the effects of using alternative and combined surface treatment methods on the repair bond strength.

2- Many researches are still needed to study and evaluate the effect of using different composite materials either as a substrate or repair materials on the repair bond strength.

\section{REFERENCES}

1. Bonstein T, Garlapo D, Jr D, Bush PJ. Evaluation of varied repair protocols applied to aged composite resin. J Adhes Dent 2005; 7: 41-49.

2. Bouschlicher MR, Cobb DS, Vargas MA. Effect of two abrasive systems on resin bonding to laboratory-processed indirect resin composite restorations. J Esthetic Dent 1999;11:185-199.

3. Brosh T, Pilo R, Bichacho N and Blutstein R. Effect of combinations of surface treatments and bonding agents on the bond strength of repaired composite. J Prosthet Dent 1997; 77:122-126.

4. Da Fonte Porte Carreieo A, Dos Santos Cruz CA, Vergani CE. Hardness and compressive strength of indirect composite resins: effects of immersion in distilled water. J Oral Rehab.2004;31:1085-9.

5. DeSchepper EJ, Tate WH. Powers JM. Bond strength of resin cements to microfilled composites. Am J Dent 1993;6:235-8.

6. Eren D, Bektas OO, Siso SH. Can Er:YAG laser be an alternative to conventional methods for repairing composite resins?. Cumhuriyet Dent J. 2013;16(2):125132.

7. Gordan VV. Clinical evaluation of replacement of class $\mathrm{V}$ resin based composite restorations.J Dent. 2001 Sep;29(7):485-8.

8. Hannig C, Laubach S, Hahn P, and Attin T. Shear bond strength of repaired adhesive filling materials using different repair procedures .J Adhes Dent. 2006; 8: 35-40.

9. Ikejma I, Nomoto R, McCabe JF. Shear punch strength and flexural strength of model composite with varying filler volume fraction, particle size and silanation. Dent Mater. 2003;19(3):206-11.

10. Joulaei M, Bahari M, Ahmadi A, Oskoee SS. Effect of different surface treatments on repair micro-shear bond strength of silica- and zirconia-filled composite resins. J Dent Res Dent Clin Dent Prospect. 2012; 6(4) :131-137

11. Junior S, Ferracane J, Bona A. influence of surface treatments on the bond strength of repaired resin composite restorative materials. Dent Mat .2009; 25(4):442-51.

12. Lung CY, Matinlinna JP. Aspects of silane coupling agents and surface conditioning in dentistry: An overview. Dent Mater 2012;28:467-77.

13. Mandikos M, McGivney G, Davis E, Bush P, Carter J. A comparison of the wear resistance and hardness of indirect composite resins. J Prosthet Dent 2001;85:386-95.

14. Matinlinna JP, Vallittu PK. Bonding of resin composites to etchable ceramics surfaces- an insight review of the chemical aspects on surface pre conditioning. J Oral Rehabil.2007 Aug;34(8):622-30.

15. Moezizadeh M, Ansari ZJ, Fard FM. Effect of surface treatment on microshear bond strength of two indirect composites. J Conserv Dent. 2012; 15:228-232.

16. Nilsson E, Alaeddin S, Karlsson S, Milleding $\mathrm{P}$, Wennerbergg A. Factors affecting the shear bond strength of bonded composite inlays. Int J Prosthet 2000;13:52-8.

17. Pashley DH, Carvalho RM, Sano H, Nakajima M, Yoshiyama M, Shono Y, et al. The microtensile bond test: a review. J Adhes Dent. 1999;1(4):299-309.

18. Pashley DH, Tay FR, Yiu C, Hashimoto M, Breschi L, Carvalho RM, Ito S. Collagen degradation by host-derived enzymes during ageing. J Dent Res. 2004Mar;83(3):21621.

19. Passos SP, Ozcan M, Vanderlei AD, Leite FPP, Kimpara ET, BottinocMA. Bond strength durability of direct and indirect composite systems following surface conditioning for repair. J Adhes Dent 2007; 9: 443-447.

20. Qualtrough AJE, Satterthwaite JD, Morrow LA.,Brunton PA. Principles of Operative Dentistry. UK: Blackwell Munksgaard. 2005;156-158.

21. Roberson TM, Heymann HO, Swift EJ. Sturtevant's Art and Science of Operative Dentistry. 5th ed. USA: Mosby. 2006; 497-501.

22. Tabatabaei MF, Alizade Y, Taalim S. Effect of various surface treatments on repair strength of composite resin. J Dent TUMS. 2004; 1(4):5-11.

23. Zaghloul H, Elkassas DW, Haridy MF. Effect of incorporation of silane in the bonding agent on the repair potential of machinable esthetic blocks. Eur J Dent. 2014; 8:44-52. 